This item was submitted to Loughborough's Research Repository by the author.

Items in Figshare are protected by copyright, with all rights reserved, unless otherwise indicated.

\title{
The implications of cultural differences in laundry behaviours for design for sustainable behaviour: a case study between the UK, India and Brazil
}

\section{PLEASE CITE THE PUBLISHED VERSION}

http://dx.doi.org/10.1080/19397038.2015.1017621

\section{PUBLISHER}

(c) Taylor and Francis Ltd.

\section{VERSION}

AM (Accepted Manuscript)

\section{PUBLISHER STATEMENT}

This work is made available according to the conditions of the Creative Commons Attribution-NonCommercialNoDerivatives 4.0 International (CC BY-NC-ND 4.0) licence. Full details of this licence are available at: https://creativecommons.org/licenses/by-nc-nd/4.0/

\section{LICENCE}

CC BY-NC-ND 4.0

\section{REPOSITORY RECORD}

Spencer, Jak, Debra Lilley, and Samantha Porter. 2015. "The Implications of Cultural Differences in Laundry Behaviours for Design for Sustainable Behaviour: A Case Study Between the UK, India and Brazil”. Loughborough University. https://hdl.handle.net/2134/17634. 
The implications of cultural differences in laundry behaviours for design for sustainable behaviour: A case study between the UK, India and Brazil.

Dr Jak Spencer*, Dr Debra Lilley \& Dr Samantha Porter

Design School, Loughborough University, Loughborough, Leicestershire, LE11 3TU

*jakspencer@gmail.com

Acknowledgement: The data collection of this work was supported by grants from the Design Research Society and Santander. 


\title{
The implications of cultural differences in laundry behaviours for design for sustainable behaviour: A case study between the UK, India and Brazil.
}

\begin{abstract}
Traditional research into sustainable design has typically focused on reducing the environmental impact of products during the manufacture and disposal stages of a products' lifecycle. The last decade, however has seen an explosion of research into understanding and moderating user behaviour during the use phase of a products' lifecycle; often the most resource intensive phase. One of the biggest factors that affects behaviour is a users cultural context, however the affect of cultural context on design for sustainable behaviour has had little exploration in this relatively new research field.

In this paper the findings from in-depth qualitative research with middleincome households in Brazil, India and the UK are presented with respect to laundry behaviours. Laundry was chosen as the study topic as it is one of the world's most widespread household chores with significant resource implications. The results reveal the vast differences in laundry behaviours between the regions and the implications this has for designers looking to create new products for sustainable behaviour. Finally, changes to current theoretical models of the laundry routine and the design implications of cultural context are discussed using established cultural tools, such as Hofstede's Cultural Dimensions.
\end{abstract}

Keywords: Design for Sustainable Behaviour, culture, laundry, sustainable development

\section{1) Introduction}

Understanding the cause of behaviour and how to moderate it is useful to designers trying to change people's interactions with the products they create. Over the last decade there has been a rapidly growing research area concerned with using the theory from behavioural studies to design strategies that influence user behaviour and promote more sustainable use of products and services (Elizondo, 2011).

Lilley (2009) argues that there is an axis of influence between the user and the product that determines where the power in decision making lies 
(figure 1). At one end the user makes an informed decision to change behaviour based on real-time aural, visual or tactile information or feedback. At the other end of the axis are technology driven solutions that use intelligent technologies to dictate the mode of use entirely. Whilst in the middle is behaviour steering where designers can control user interaction without forcing behaviour.

Figure 1 - Lilley's axis of influence (2009)

Understanding this axis of influence allows the designer to position an intervention which balances the needs of the user with the nature of the targeted behaviour (Hanratty et al, 2012). Whilst powerful in their intent, these design intervention strategies can only be effective if the various approaches are correctly matched to users' needs, understanding and motivations (Hanratty et al, 2012).

Lidman et al (2011) propose a model based on Lilley's axis using strategies developed by Tang (2010) and Wever et al (2008) to suggest a classification with five strategy categories along the axis of control: Enlighten, Spur, Steer, Force and Match

Enlighten uses strategies that influence knowledge, values, and norms; Spur uses strategies to encourage sustainable behaviours (carrots and sticks); in the Steer category the sustainable behaviour is the evident choice through the design; and Force requires the user to behave in a certain way (Renström et al, 2013). In the final category, Match, no behavioural change is needed as the design of the artefact is matched to the current behaviour or behavioural intent of users (Renström et al, 2013), building on Wever's (2008) concept of functionality matching.

Other academics have built upon the behavioural theory and the factors that affect individuals in different contexts. Table 1 gives an overview of the models discussed and shows how academics within the field have collaborated to progress the research area in just a few short years.

Table 1 - Design for sustainable behaviour theory development

\begin{tabular}{|lll|}
\hline Year & Authors & $\begin{array}{l}\text { Comments } \\
\text { Develops axis of control using } \\
\text { feedback, steering \& technology. }\end{array}$ \\
\hline $\mathbf{2 0 0 8}$ & $\begin{array}{l}\text { Wever, R., Van Kuijik, J. \& } \\
\text { Boks, C. }\end{array}$ & $\begin{array}{l}\text { Develops forced functionality concept } \\
\text { as well as 2nd branch of model; }\end{array}$ \\
\hline
\end{tabular}




\begin{tabular}{|lll|}
\hline 2008 & $\begin{array}{l}\text { Elias, E., Dekoninck, E. \& } \\
\text { Culley, S. }\end{array}$ & $\begin{array}{l}\text { functionality matching. } \\
\text { Argues each behavior has a theoretical } \\
\text { minimum energy requirement }\end{array}$ \\
\hline 2010 & Tang, T. \& Bhamra, T. & $\begin{array}{l}\text { Develops strategies further and } \\
\text { integrates Triandi's TIB model (1977) } \\
\text { and Anderson's framework for the } \\
\text { acquisition of cognitive skill (1982) }\end{array}$ \\
\hline $\mathbf{2 0 1 0}$ & $\begin{array}{l}\text { Lockton, D., Harrison, D. \& } \\
\text { Introduces real world examples through } \\
\text { a series of lenses to inspire designers. }\end{array}$ \\
\hline $\mathbf{2 0 1 1}$ & $\begin{array}{l}\text { Lidman, K., Renström, S. } \\
\text { \& Karlsson, I. }\end{array}$ & $\begin{array}{l}\text { Develops Tang (2010) \& Wever et al } \\
\text { (2008) models further with enlighten, } \\
\text { spur, steer, force and match. }\end{array}$ \\
\hline $\mathbf{2 0 1 2}$ & Zachrisson, J. \& Boks, C. & $\begin{array}{l}\text { Uses the axis but builds in further } \\
\text { antecedents and factors such as } \\
\text { values/norms, intention/constraints \& } \\
\text { importance/annoyance to guide change }\end{array}$ \\
& & $\begin{array}{l}\text { Proposes user centred method to } \\
\text { create interventions based on DfSB } \\
\text { strategies \& framework to asses } \\
\text { successfulness of DfSB interventions }\end{array}$ \\
\hline $\mathbf{2 0 1 3}$ & Wilson, G. & $\begin{array}{l}\text { Develop the 5 pathways model to aid } \\
\text { selection of DfSB strategies at the start } \\
\text { of a design project. }\end{array}$ \\
\hline $\mathbf{2 0 1 3}$ & $\begin{array}{l}\text { Renström, S., Strömberg } \\
\text { H., \& Selvefors, A. }\end{array}$ \\
\hline $\mathbf{2 0 1 3}$ & Lilley, D \& Wilson, G. & $\begin{array}{l}\text { Integrates evaluation criteria and } \\
\text { ethical assessment tool. }\end{array}$ \\
\hline
\end{tabular}

The rapid advancement of the theoretical element in this relatively young research field is testament to the interest and importance of it. However, antecedents of behaviour are highly influenced by cultural factors and therefore understanding the cultural implications of the strategies to design for sustainable behaviour are of paramount importance to advance the design for sustainable behaviour field. A recent study by Elizondo (2011) attempted to understand how culture could inform Lilley's DfSB strategies, however, it culminated in a methodological approach for gaining empathy with users in different cultures, rather than a theoretical understanding of what influences behaviours in different cultures and a process of informing designers looking to change behaviours.

One of the objectives of this research was to investigate the behaviours of individuals from different cultural contexts regarding their interactions with key resources as well as the external factors that may influence these behaviours.

Understanding cultural characteristics, particularly in countries of different levels of development, is complex, however Hofstede (1980) introduces five key cultural dimensions to aid understanding. One of the key 
differences between developed and developing countries regarding their cultural identities is the notion of individualism or collectivism as defined by Hofstede (1980). The most common and noticeable differences between Hofstede's five 'Cultural Dimensions' outlined in table 2 below is that developing countries such as those in Asia, Africa, and Latin America show very high rates of collectivism, compared to the high rates of individualism seen in developed nations such as the USA and Europe. In a collectivist society individuals are integrated into strong, cohesive groups such as the extended family, religious, political or social groups; whilst in an individualist society ties between individuals are loose and people are generally expected to look after themselves (Hofstede, 1980). This cultural difference between societies can play a large part in the protection and sharing of resources that are, ultimately, meant to be accessible to all.

Table 2 - Hofstede's Cultural Dimensions (1980)

\begin{tabular}{|ll|}
\hline $\begin{array}{l}\text { Cultural Dimension } \\
\text { Index }\end{array}$ & Meaning \\
& $\begin{array}{l}\text { How much the less powerful members of } \\
\text { organisations and cultures accept and expect that } \\
\text { power is distributed unequally e.g. in Australia the } \\
\text { power ratio between normal employee and boss is } \\
\text { low where as in China it is high. }\end{array}$ \\
\hline $\begin{array}{l}\text { Collectivism I } \\
\text { Individualism }\end{array}$ & $\begin{array}{l}\text { How much members of the culture associate } \\
\text { themselves with a group or just do things typically for } \\
\text { themselves. The UK and USA have high } \\
\text { individualism, where as Latin America has low } \\
\text { individualism. }\end{array}$ \\
\hline $\begin{array}{l}\text { Masculinity I } \\
\text { Femininity }\end{array}$ & $\begin{array}{l}\text { Masculine cultures have high values in } \\
\text { feminine cultures have high values in relationships } \\
\text { and quality of life e.g. Japan vs Denmark. }\end{array}$ \\
\hline $\begin{array}{l}\text { Uncertainty } \\
\text { Avoidance Index } \\
\text { (UAI) }\end{array}$ & $\begin{array}{l}\text { Avoiding anxiety by minimising uncertainty. High UAI } \\
\text { are cultures with rules and structured activities e.g. } \\
\text { Japan vs Jamaica. }\end{array}$ \\
\hline $\begin{array}{l}\text { Long-Term } \\
\text { Orientation }\end{array}$ & $\begin{array}{l}\text { In long term oriented societies, people value actions } \\
\text { and attitudes that affect the future: } \\
\text { persistence/perseverance, thrift, and shame. In short } \\
\text { term oriented societies, people value actions and } \\
\text { attitudes that are affected by the past or the present } \\
\text { e.g. China vs UK. }\end{array}$ \\
\hline
\end{tabular}

There is a distinct lack of literature specifically related to the effect that culture has on sustainable behaviour. The DfSB strategies and cultural 
dimensions offer an interesting platform for which to develop research regarding the cultural aspects of DfSB; and this research is presented in this paper with regard to laundry behaviours.

\section{2) Laundry Literature}

Laundry is an important area of study as it is one of the most widespread household chores in the world and plays a large part in the everyday logistics of running a house and establishing self-identity (Pakula \& Stamminger, 2010; Pink, 2005). It is a multifaceted process that involves much more than just cleanliness. Social and technical aspects of laundry (what needs to be washed, when does it need to be washed, what tools will be used, by whom) make it a complex household system (Shove, 2003).

Laundry is an incredibly energy intensive form of housework. Whilst years ago it was hard, mechanical work (and in some countries still is), today washing machines do the majority of the work with the use of water, electricity and chemical substances (Pakula \& Stamminger, 2010). Working out the precise energy consumption of the laundry process is, however, very difficult as the system is made up of a huge range of variables influenced by technological, cultural, social and moral norms (Shove, 2003). The age and type of a washing machine affects the energy intensity of the act of laundering as much as the climate of the region in which it takes place or the upbringing of the launderer (Laitala et al., 2011). However one thing is clear, the most energy demanding time during the lifecycle of clothing is the use stage (Madsen et al, 2007 - cited in Laitala, 2011).

In recent years there have been great technological advances in the energy efficiency of washing machines. In the last 10 years for example, a 30\% water and electricity efficiency improvement has been achieved in horizontal axis machines in Europe, with all machines sold in Europe now belonging to the energy label category 'A' (Pakula \& Stamminger, 2010). These technological improvements have, however, tended to be counteracted by the laundry habits of consumers, as they decide the method and frequency of washing and drying (Laitala et al., 2011). A study in the Netherlands showed that the amount of laundry washed per person has increased by a factor of 6.7 since 1950 and this trend is common amongst other 'Western' countries (Uitdenbogerd, 2007). Part of the reason for this is that energy consumption, particularly when bound up by routine and habit with the use of tools or appliances in a household environment, is simply invisible to the consumer (Shove, 2003). Consumers tend to associate environmental issues with clothing at the end of life, giving it to charity or recycling, rather than throwing it away (Laitala et al, 2011). However, washing habits and the energy implications of those habits vary greatly between cultures with behaviours adjusted to local conditions (ibid). 
Pink suggests that sensory experiences are linked to cultural values which can be changed (Pink, 2005). When washing machines were first introduced manufacturers cleverly redefined 'cleanliness' as 'whiteness' rather than the removal of germs to change the belief that boiling was needed. Nowadays the need for washing clothes has shifted again, with consumers washing more frequently for 'freshness' of clothes rather than cleanliness, invoking important sensory attachments to the process of laundering (Pink, 2005, Shove, 2003). Indeed it can now be seen that clothes are washed purely out of habit rather than the build-up of any visible dirt (Mintel, 2011; Laitala, 2011).

Shove suggests thinking of the laundry as a 'system of systems' "formed, shaped and given meaning by a complex of 'ingredients': by what there is to wash, what washing involves (who does it, with what tools), and when and why it's done" (Shove, 2003b; p401). These 'ingredients' are dimensions in their own right, but are interdependent on other dimensions; changing one dimension will have knock on effects on the other dimensions, and change the system as a whole.

Continuing the mechanical metaphors, Shove describes the 'service' of laundry as an "assembly of cogs (textiles; tools, e.g. detergents, washing machines; rationales; skills and expertise) each of which can turn one way or another, but that together constitute the system as a whole" (Shove, 2003b; p405). Some cogs will be more dominant, such as the washing machine which has an ability to re-script behaviour, whilst individual experience will determine the arrangements of the cogs according to differing ways of doing the laundry

In the context of laundry it is important to pay attention to the role of culture on the dynamics of consumption and behaviour. So-called 'normal behaviour' is steeped in cultural preferences and it is the co-evolution of these preferences through the interaction of different socio-technical systems that determines the resource efficiency of a behaviour (Lin \& lyer, 2006).

In the UK, ownership of washing machines is almost universal amongst households (96\%). Tumble dryer ownership rose slightly from 54\% of households in 2001 to $57 \%$ of households in 2010 (ONS, 2011). In 1998 the British Consumers' Association found that almost everyone had outside drying facilities, but a third of all tumble dryer owners used the tumble dryer all year round. If the weather was good the average dryer load per week was four, if the weather was bad, the average was six (BCA-RandTC, 1998 - cited in Uitdenbogerd, 2007). However in more recent studies this trend has been seen to be decreasing, with a higher tendency to line dry clothing (Mintel, 2011). Two to three washing loads per week is generally the most common, 
with household size and presence of children the biggest influence on wash frequency.

In Brazil on the other hand, washing machine ownership is much lower. In 2009, 41.5\% of households had a washing machine (IBGE, 2009). They are however experiencing a surge in growth for consumer goods. In 2006, $35.8 \%$ of households owned a washing machine, showing a total growth of $5.3 \%$ in 3 years (IBGE, 2006). Washing is done an estimated $3.9-5$ times per week (Corbett et al., 2011) and nearly always at low temperatures (Greendex, 2010).

In India, 14\% of urban households and $7 \%$ of rural households own a washing machine (Euromonitor, 2011), however they are expected to see rises of up to $19 \%$ by 2015 (ibid). According to a study on global households, $65 \%$ of participants are likely to wash clothes in cold water, 2 nd only to Brazil (Greendex 2010).

Figures that show the exact percentage of which type of washing machine technology is most prevalent in each country are scarce. Estimates suggest that in Western Europe 98\% of households have horizontal axis washing machines (Pakula \& Stamminger, 2010). Exact figures for Brazil are not available; however anecdotal evidence suggests that it is a country with a 'top-load' culture (Industry Today, 2012) that has traditionally followed technology from the USA with over $90 \%$ of households owning a vertical axis machine (Pakula \& Stamminger, 2010). Horizontal axis machines are approximately 50\% more expensive in Brazil with prices starting at $R \$ 1500$ (US\$650), compared to R $\$ 1000$ (US\$430) for vertical axis machines from major brands. Again data is scarce from India; however it is apparent that it is traditionally a 'top loading' country with increasingly high sales for front loading models because of the perceived benefits (DNA, 2012). Vertical axis machines typically dominate the lower end of the economic range, with some basic horizontal axis machines coming it slightly higher at approximately rs15000 (US\$250).

Whilst there are cross-cultural studies in laundry (Pakula \& Stamminger, 2010; Lin \& lyer, 2006), they tend to focus on quantitative technical data and compare countries with readily available technical machine information from Europe and Japan. Studies comparing the specific laundry habits of consumers from different cultures, particularly in emerging markets, are limited.

\section{3) Methodology}

To investigate the implications of cultural differences in laundry behaviours in-depth user research was conducted in three sites; Curitiba, 
Brazil; Bangalore, India; and Loughborough, UK. Three data collection techniques were used; contextual observation, household tour, and contextual interview. These methods collectively explored the everyday behaviours of the household routine as well as participant's perceptions of the laundry process. The in-context interview was carried out by the investigator in the participant's home. "Contextual interviews are an effective method for eliciting user requirements because they are a combination of interview and observation" (Guðjónsdóttir \& Lindquist, 2008; p168). The method is useful as the participants can give more relevant descriptions when they are in the environment around the relevant tools. The investigator also has a clearer understanding of the environment, observes the tools and activities performed and has a better chance to ask relevant questions (ibid).

Questions were asked related to the themes of laundry in the home and notes were taken along with recording the interview on a dictaphone. The themes included questions on pre-treatment of clothes, the washing routine, drying, post-treatment and general laundry questions. The interview and observation had a flexible feel to it and was designed to draw out information about the participant and their routines within the home.

The household tour allowed the participant to narrate relevant information regarding the research subject to the investigator. The household tour was conducted after the contextual interview and usually led to the contextual observation of the laundry procedure. Like the contextual interview, the household tour was kept fairly informal and led by the participant, with the investigator interjecting if there was a particular aspect of interest where more details were required.

The study was conducted in 6 households in the UK and India and 7 in Brazil (19 in total).

Brazil, India and the UK were chosen as study areas as they show extensively different cultural characteristics with a contrast in levels of economic development and environmental rankings, whilst also having large populations and established or growing markets (Spencer \& Lilley, 2012). Bangalore, Curitiba and Loughborough were chosen for having either an established or emerging consumer class, as well as for practical reasons, with research connections at organisations in all locations. Funding for data collection was provided by the Design Research Society and Santander.

Participants for the intensive study were young, middle income consumers. The tables below (Tables 3, 4 and 5) show the characteristics for the participants. 


\begin{tabular}{lllllll}
\hline & UK01 & UK02 & UK03 & UK04 & UK05 & UK06 \\
\hline Gender & F & F & M & F & M & M \\
Age & $30-35$ & $30-35$ & $20-25$ & $25-30$ & $25-30$ & $30-35$ \\
$\begin{array}{l}\text { Household } \\
\text { members }\end{array}$ & 2 & 2 adults, 2 & 2 & 4 & 2 & 2 adults, 1 \\
children & & & & child \\
$\begin{array}{l}\text { Occupation } \\
\text { Washing }\end{array}$ & Administration \\
$\begin{array}{l}\text { machine } \\
\text { type }\end{array}$ & Front Load & Front Load & Front Load & Front Load & Front Load & Front Load \\
\end{tabular}

\section{Table 4: Indian Participants}

\begin{tabular}{ccccccc}
\hline & IN01 & IN02 & IN03 & IN04 & IN05 & IN06 \\
\hline Gender & M & M & F & M & F & F \\
Age & $35-40$ & $30-35$ & $30-35$ & $25-30$ & $35-40$ & $30-35$ \\
$\begin{array}{c}\text { Household } \\
\text { members }\end{array}$ & 2 & $\begin{array}{c}\text { 2 adults, } 1 \\
\text { child }\end{array}$ & 2 adults, 1 child & 2 & 2 adults, 2 & 2 \\
Cccupation & Journalist & Engineer & Administration & Architect & Housewife & Translator \\
$\begin{array}{c}\text { Washing } \\
\text { machine } \\
\text { type }\end{array}$ & Front Load & Top Load & Front Load & Front Load & Front Load & Top Load
\end{tabular}

Table 5: Brazilian Participants

\begin{tabular}{|c|c|c|c|c|c|c|c|}
\hline & BR01 & BR02 & BR03 & BR04 & BR05 & BR06 & BR07 \\
\hline Gender & M & $\mathbf{F}$ & M & $\mathbf{F}$ & $\mathbf{F}$ & F & $\mathbf{F}$ \\
\hline Age & $25-30$ & $30-35$ & $20-25$ & $30-35$ & $20-25$ & $30-35$ & $25-30$ \\
\hline $\begin{array}{l}\text { Household } \\
\text { members }\end{array}$ & 3 & $\begin{array}{l}2 \text { adults, } 1 \\
\text { child }\end{array}$ & 3 & 2 adults & 1 & $\begin{array}{l}2 \text { adults, } 1 \\
\text { child }\end{array}$ & 3 \\
\hline Occupation & Banking & $\begin{array}{l}\text { Masters } \\
\text { Student }\end{array}$ & Accounting & Lawyer & Copyrighter & $\begin{array}{l}\text { Shop } \\
\text { owner }\end{array}$ & Admin \\
\hline $\begin{array}{l}\text { Washing } \\
\text { machine } \\
\text { type }\end{array}$ & Top Load & Top Load & Top Load & Top Load & Top Load & Top Load & $\begin{array}{l}\text { Front } \\
\text { Load }\end{array}$ \\
\hline
\end{tabular}




\section{4) Findings}

The following main findings were drawn from the data collection with relevance to the laundry routine.

In India and Brazil, clothes were predominantly dried in the sun, as there is fairly predictable weather. Participants found it hard to dry clothes when it is wet or cold and occasionally used the tumble dryer when it was hard to naturally dry clothes. In the UK, naturally drying clothes outside was often overlooked because of the changeable weather with half of UK participants using the tumble dryer regularly.

In Brazil, the most common time to do the laundry was on the weekend, whilst in India it was throughout the week depending on when the house-help is available. House help was common to all the Indian participants either daily or weekly. Brazilian participants also used house-help, however usually only once a fortnight. None of the UK participants employed anyone to help with household chores.

Across the three sample sites participants either washed clothes based on their sensory perceptions of dirtiness (look/smell dirty) or time related (worn for two days). This was independent of the sample context.

In Brazil the use of a 'laundry room' or designated area for the laundry process was common. The only participant without this room used the tumble dryer because she didn't like to have wet clothes draped around the house.

In Brazil and India the participants bought washing machines based on the price, brand, energy consumption or size. In the UK the participants either didn't have a say in which machine was purchased (rented accommodation) or bought whichever machine was cheapest. Detergent was purchased based on habit of what had previously been used.

In Brazil 6 out of the 7 participants owned a vertical axis washing machine that used cold water, however nearly all participants aspired to own horizontal axis machines and wash in warm water for the perceived better cleaning ability. In India there was a mix of machine types (4 horizontal, 2 vertical axis) with participants agreeing that horizontal axis machines were better. All participants in the UK had horizontal axis machines.

Participants in all three sites were not well informed on the energy consumption of their washing machine or laundry behaviours beyond purchasing the machine based on the energy rating scheme (A rated). 
Consumption and use behaviours were heavily linked to good or bad past experiences and the influence of other people (friends and family).

In India the use of hot water was linked to hygiene (washing when someone is ill) rather than cleanliness, whilst in the UK, hot water was more associated with cleanliness. Most participants in Brazil wanted to wash in warm water for the perceived benefits but admitted they were worried about price.

\section{5) Discussion}

The UK sample all had front loading machines, by far the most common type of machine in the UK, whilst in Brazil all the participants had a top-load, again - in keeping with the typical machine type of the country. Interestingly, nearly all participants with a top-loading machine desired a frontloading machine due to their perceived better cleaning ability and water efficiency. There has been a small growth in sales in front loading machines in Brazil in recent years (Electrolux, 2011) and this is expected to rise rapidly in the future. India is further ahead in this transition with a large growth in the sales of frontloading machines - replacing top-loaders, represented in the sample with a 60/40 split of front loaders to top loaders. This small change in washing technology, however, can have considerable consequences.

Firstly, the benefits of the front-loading machine, as well as the water efficiency, are the space saving ability as it can be more integrated into the household, often under counters in the kitchen or bathroom. However the benefit of saving space often comes at the cost of more complicated installation. Due to the tight spaces the machine is squeezed into, it often has to be more integrated into the plumbing and electrical system of the house. A front loading machine will often have two water inputs (hot and cold), directly from the plumbing system of the house and a drainage facility again linked to the plumbing system. By contrast, the top loading machines, particularly those seen in Brazil, are much simpler. One input which attaches to a standard tap (found in Brazilian laundry rooms), and one output (drainage) which hooks over the laundry sink and pours down the standard plug hole (Figure 2). The front-loading machine requires someone very competent at DIY or a professional plumber to install, whilst the top loading machine can quite easily be explained and installed by most users - straight from the shop.

Figure 2 - The plumbing of a top load machine, Brazil 
This has implications on the users' knowledge of the relevant inputs and outputs of the machine. With a top load machine, they have installed it themselves and understand the link between the input from the tap (often having to turn the tap on and off before and after use) and the output in terms of drainage. In a front load system, installed by a professional, this link between inputs and outputs is lost - and the machine becomes a ubiquitous white box that washes clothes. This may be part of the reason why water and energy efficiency is more prominent in Brazil and India than in the UK sample.

The lack of cognitive thought process about the inputs and outputs of the device paves the way for more unsustainable behaviours to creep in. It doesn't take long before the user clicks the 'better', 'harder', or 'tougher' button on the generic white box with longer cycle times and higher temperature washes as the user is detached from the cause and consequence of the action. A user that has installed the machine themselves, as in the case of top-loads, will have more of an understanding of the inputs and outputs; in this case, having to turn the tap on to fill the machine with water and seeing the dirty water drain out via the sink.

This also can be seen with the water efficiency of the machine. Whilst a front loading machine is more water efficient, once again, the efficiency gain is taken out of the hands (and thought process) of the user, instead using technology to remove any control from the user. Although the top load machine technology may use more water - the act of filling the machine is in the complete control of the user and is more visually understandable (similar to filling up a bucket). Users understand an efficient level of water to wash at and can see when they have filled it too high and wasted water - a visual stimulus that is lost in front load machines.

Furthermore, the simple change from a top load to a front load has interesting consequences on the responsibility of purchasing the machine. As previously stated, the front loading machine becomes more integrated into the house, often under the sink in the kitchen, and plumbed into the central household plumbing system. As a consequence, the washing machine becomes an integral part of the kitchen rather than a standalone appliance. In the samples, all the UK participants who were living in rented accommodation stated that the washing machine was already there when they moved in. In contrast, the Brazilian sample that lived in rented accommodation all purchased the washing machine as their own appliance after moving in.

The shift from having a stand-alone appliance to an integrated one changes the responsibility of the purchaser in rented accommodation. With a top-load, the end user is usually the one purchasing the machine and therefore has control over the type, style, brand, and functionality of the machine they buy. A front loading machine on the other hand, integrated into 
the house, is bought by the landlord of the premises, with the end user of the machine often not around to decide which would be most suitable to buy. Once again control is taken away from the end user.

Although seemingly a simple change, it is clear there are far reaching consequences between a top-loading and a front loading machine. In a frontloading machine the control and understanding of the system is taken away from the user and replaced by technological efficiencies. In reality, a user with understanding and control of a system is more likely and able to behave in a desired way. Taking heed of this will be important in future designs of front loading machines, combining technological efficiencies with user understanding and control, as they continue to grow rapidly and replace toploading models.

\section{The Importance of Information}

The participants showed that information is key in their decision making and behaviour. Nowhere was this more clear than in the decision to purchase the machine based on the energy rating scale. In both Brazil and India participants only bought machines based on the highest energy rating as they thought this was all they could do to save energy.

This draws out some interesting insights. Firstly, participants in Brazil and India are generally happy to purchase efficient technologies, especially if the benefits are made clear to them in an easy to understand system. A simple rating scale puts one technology or product above another and participants can easily see the benefits, especially if both products have very similar functionality.

By doing this however, the user has already consciously made the effort to be more resource efficient. They have put their trust into the product based on the information that they have been given, and thus believe that by buying an efficient machine they have done all they can to be more resource efficient. When questioned what they do to be more resource efficient, they all pointed towards the energy rating scale of the appliance, but rarely questioned their own behaviour or interaction with the appliance as a means of being efficient. Part of the reason for this is that it is hard to market a product based on the potential efficiencies of using it in a certain way, where as a new technology or technical process in the machine can easily be marketed (e.g. Now uses 30\% less water!). Companies will struggle to advertise potential energy savings to consumers based on projections of expected behaviour.

Similarly the energy rating scale could also be a potential source of confusion by informing consumers they are making an energy efficient 
decision when all of the alternatives may not be accounted for. As an example, a consumer may buy a tumble dryer with an ' $A$ ' rating and assume they have 'done their bit' to be more resource efficient, without fully considering the alternatives such as reorganising their routine to dry clothes naturally.

In this way the information that consumers are fed is of the upmost importance. Energy rating scales are a great way of easily portraying the technological efficiencies of an appliance, and have, as the samples show, had an enormous impact in driving sales of efficient machines. However, an over-reliance on such a system should be viewed with caution. Just because the appliance has been labelled as the most efficient does not mean it will be the most suitable product for everyone or in every context. As an example we can look at the Indian participant who had purchased a washing machine based on the advertised efficiencies, but noted he would prefer it if it had a shorter spin cycle, as clothes can easily be dried just as well outside, and this would take up less cycle time and energy. Similarly the only participant in Brazil to use a dryer did so because they did not have a big enough laundry space to dry clothes and didn't like the aesthetic of clothes drying around the home. Although they purchased an efficient model, surely a more efficient behaviour is that of the other Brazilian participants with a natural drying space.

\section{The Built Environment}

The space in which an individual operates has a substantial importance in shaping activities around the home. All too often the design of an artefact is centred on precisely that; the artefact. In reality, the spaces around all the 'touch-points' of a system will shape a behaviour. In the laundry example, designing an efficient machine is one part of the challenge, but the factors that will greatly impact the behaviour are the other spaces in the process; where the clean clothes are kept, where the dirty clothes are collected, where the washing machine is located, and where the clothes are dried. Each of these spaces are part of the subtleties of everyday life that affect behaviours in a huge way.

In Brazil the downsizing of the laundry area within property has been a direct result of the increasing consumer class; being able to afford automatic washing machines, the need for house-help has decreased and the price of labour has increased. As a result modern properties have been designed with much smaller spaces for laundry, and with the move to front loading machines, this area may be abandoned altogether. This clearly shows a direct link between how the design of a product directly influences the space around it; and underlines the importance of the relationship between industrial design and architecture. By reducing the laundry space and moving the machine into the kitchen the type of machine changes - with front loading machines being more favoured to top loading machines for their space saving ability. The 
drying process will also change as people have to find new places to dry their clothes where once they would have had their own separate room.

The above point highlights the interconnectedness of design with all aspects of our everyday lives. In the example in Brazil, the change in societal structure (increased disposable income) together with the design of new technologies (front loading washing machines) has begun to change the architectural layout of modern buildings. If we are to move to more sustainable household behaviour we have to integrate the design of spaces with the design of products. The links between architecture and product design have to be strengthened so that the interaction by the user with the appliance, and its correlating 'touch points' in the given environment, promotes sustainable behaviours.

\section{A Sense of Time}

Across all the regions there were two types of 'washers'; those that washed in relation to time; and those that washed through a sense of smell, sight or touch.

In general, those who washed by time had strict 'policies' about when an item should be washed; usually a 'one wear, one wash' policy for shirts and t-shirts and similar $2-5$ wear policy for trousers.

Those who washed by sense would only wash a garment if it was visibly dirty; i.e. with a stain, or if it smelt dirty; i.e. from sweat. Interestingly these two types of 'washers' were interchangeable depending on their personal circumstance, with some participants sticking to a 'time related wash' for their work clothes, but a 'sense related wash' for their casual clothes. In this way the role of laundry is strongly linked to routine and habit.

The interesting point here is that the technique used for establishing whether something is dirty, ultimately the users' perception of cleanliness, is a culturally independent factor, with participants in different contexts having very different views; yet this perception is created by factors that are culturally significant, such as their upbringing, other people around them and their views. One Indian participant noted that they wash jeans and 'harder items' every 2 or 3 months (IN01), a substantial difference to other participants both in India and in the UK and Brazil.

Previous studies have alluded to the need to understand resource intensive behaviours in different cultures and form a method for more successful transfer of sustainable behaviours with the implementation of new technologies. However, transferring a new technology to a new cultural context does not mean the technology or desired behaviours will be adopted successfully. Transferring behaviours between cultural contexts requires a 
deep-rooted understanding of the social, cultural and personal norms of the region. The findings could offer innovative solutions to a household chores in a more modern service based economy; however for the successful transfer of behaviours the cultural, societal and personal norms need to be identified and matched.

Understanding the cultural factors therefore not only allows the designer to build empathy with users in unfamiliar contexts, but also allows the designer to understand the causes of a desired behaviour and transfer this to a new context. This significantly improves the prospects of the adoption of a new product in an unfamiliar cultural context.

\section{Methodological Implications}

The research has been conducted with young, middle income consumers and this has provided a good comparison base for laundry behaviours across the three sample sites. Participants were chosen from these groups of society as they are a large consumer of modern household appliances, with an available disposable income and an ability or desire to change consumption habits based on societal norms/cues. Despite this, there are limitations with having a limited demographic range, particularly when considering the multi-generational and familial concept of the laundry. Behaviours from other generational groups may be considerably different based on previous knowledge or context and therefore further research into this area would have to be conducted to get an overview of laundry behaviours in society as a whole.

\section{6) Conclusions}

The findings highlight aspects of the laundry routine that are culturally significant and aspects that are culturally independent. Cultural significance refers to the elements of the washing process that were common amongst the samples in their respective regions; often contextual factors at a macro level. Culturally independent elements refer to the differences between the individuals throughout the samples; often influenced by perceptions of particular individuals. In the example of laundry we can look at Shove's Whirlpools of Laundering (2003). In her model Shove defines the five whirlpools of the laundry process as: How to launder, the tools of laundry, when to launder, what to launder and why launder.

In reality this could be broken down and simplified further. In an updated model the tools of laundering would remain the same (the specific physical things used in the process) and are culturally significant; 'Why launder' could be summarised better by a new category of 'perceptions' (the views and aspirations of the consumer) and would be culturally independent; 
and the categories what to launder, how to launder, and when to launder could all be merged into one category - the laundry routine, which is ultimately influenced by both culturally significant and culturally independent factors (figure 3).

Figure 3 - Redefining Shove's Whirlpools of Laundry

The research can also be used to aid the development of Hofstede's cultural dimensions to align with design for sustainable behaviour strategies enabling designers to explore opportunities typically afforded to economists and business strategists.

By looking at Hofstede's cultural dimensions we can not only design products that are more relevant to use in different cultural contexts, but also align them with the design for sustainable behaviour strategies introduced at the beginning of the paper. Introducing a community based laundry system, for example, may be much more widely accepted in collectivist societies rather than individualistic ones. Similarly strategies such as gameification, often used to incentivise sustainable behaviour, will be more successful if targeted toward masculine cultures which value competitiveness and ambition, whilst strategies such as creating an emotional attachment will be more successful for feminine cultures valuing quality of life and wellbeing.

In this way, this research has not only highlighted the significant differences of laundry behaviours in Brazil, India and the UK, but also enabled an understanding of the importance of exploring the cultural differences in behaviour when looking to design for new markets. Cultural context is one of the biggest influences on behaviour and it can therefore be used as inspiration for the transfer of behaviours between contexts to reduce the resource implications of everyday household behaviours.

One of the important considerations when looking at the redesign of any laundry system will be the relatively long replacement cycle of laundry appliances. As the sample shows, the washing machine is not something that people change regularly, and it usually requires a large life change, such as moving house, a new kitchen, the current machine malfunctioning, or an increase in income (such as in emerging economies) to decide to go and buy a new one. In this sense, any behaviour that is adopted by the introduction of a new technology or design will remain with the user for a long time and will almost certainly alter their habits of washing. 
This will not only have a dramatic effect on the original user, but also a knock on effect over generations. As the samples have shown, a great deal of household behaviours are influenced by upbringing, with the behaviour of the mother being the strongest influence in the laundry example. With this in mind, a significant change in the design of a process to promote more sustainable behaviours will have far reaching consequences, not just in the present, but for future generations too.

\section{7) Implications for Design Practice}

The research can lead to potential improvements in design practice. It allows designers to gain a deeper understanding of cultural issues relevant in the design of new products or services. The cultural dimensions enable designers to extrapolate behaviours within a cultural context and provide a non-prescriptive tool to innovate in different contexts. Furthermore, the cultural dimensions can be used by designers to compare and contrast behaviours in different cultural contexts to aid with ideation and inspiration for innovative new designs. The research aids the understanding of behaviours in different contexts whilst linking to Hofstede's Cultural Dimensions to establish a link between the possibilities of transferring sustainable behaviours between contexts. Therefore, whilst still early in its development, the research could be used by design practice for both ideation of new designs and implementation in new contexts.

\section{8) Further Work}

The research can be taken further by combining the behavioural theory with the cultural dimensions to create a design tool which enables designers to understand and implement changes to designs based on cultural observations. Further validation can be added to this theory by researching other household behaviours in new cultural contexts and comparing the results. The new design tool can then be tested in the form of a design challenge with international designers using the research to create concepts for design problems in different cultural contexts.

\section{9) References}

Corbett, C., McWeeney, D. \& S. Walsh. 2011. Unilever in Brazil (1997 - 2007) 'Marketing Strategies for Low-Income Consumers'. Available at: http://www.slideshare.net/seanpauldcu/marketing-strategies-for-lowincome-consumers-unilever. Accessed: April 2012. 
DNA. 2012. Front loading washing machines vs. top-loaders. Available at: http://www.dnaindia.com/money/1716258/report-front-loading-washingmachines-vs-top-loaders Accessed: August 2013.

Electrolux. 2011. Laundry products. Annual Reports 2011. Available at: http://annualreports.electrolux.com/2011/en/operations/electroluxprodu cts/laundryproducts/laundry-products.html Accessed 2013.

Elizondo. 2011. "Designing for sustainable behaviour in cross-cultural contexts: a design framework". Design School. Loughborough University.

Euromonitor International. 2011. Home laundry appliances in India. Available at: http://www.euromonitor.com/home-laundry-appliances-inindia/report. Accessed: April 2012.

Greendex. 2010. Greendex: Survey of Sustaiable Consumption. National Geographic. Available at: http://environment.nationalgeographic.com/environment/greendex/. Accessed: December 2010.

Guðjónsdóttir, R. \& Lindquist, S. 2008. "Personas and scenarios: Design tool or a communication device?" In Proceedings of COOP'08, Carry Le Rouet, France, pp. 165-176.

Haratty, M., Bhamra, T., \& Mitchell, M. 2012. "Digital Design for Sustainable Behaviour: A conceptual framework to guide design intervention." Proceedings of $\mathrm{BCS} \mathrm{HCl} 2012$ Workshops Using Technology to Facilitate Behaviour Change and Support Healthy, Sustainable Living. Available at: http://ewic.bcs.org/upload/pdf/ewic_hci12_sl_paper5.pdf [accessed: April 2013].

Hofstede, G. 1980. Culture's consequences: International differences in workrelated values. Beverly Hills, CA: Sage.

IBGE. 2009. National Household Sample Survey. Available at: http://www.ibge.gov.br/home/estatistica/populacao/trabalhoerendiment o/pnad2009/tabelas_pdf/sintese_ind_6_4.pdf . Accessed: April 2012. Industry Today. 2012. "MUELLER ELETRODOMÉSTICOS: A Whole New Cycle." Volume 15, issue 2. Available at: http://industrytoday.com/article_view.asp?ArticleID=2884. Accessed: January 2013. 
Laitala, K., Boks, C. \& I.G. Klepp. 2011. "Potential for environmental improvements in laundering." International Journal of Consumer Studies 35, 254-265. Blackwell Publishing Ltd.

Lidman, K.M.E., Renström, S., Karlsson, M.I.C., 2011. "The green user. Design for sustainable behaviour". IASDR Conference 2011, Diversity and unity, Delft, the Netherlands, pp. 1-12.

Lilley, D. 2009. "Design for sustainable behaviour: strategies and perceptions." Design Studies, 30(6): 704-720.

Lin, J. \& M. Iyer. 2006. "Cold or hot wash: Technological choices, cultural change, and their impact on clothes-washing energy use in China". Energy Policy 35, 3046-3052.

Mintel. 2011. Laundry Habits - UK. Available at http://oxygen.mintel.com/sinatra/oxygen/display/id=600869. Accessed: April 2012.

ONS. 2011. Ownership of consumer durables increases into 2010. Available at: http://www.ons.gov.uk/ons/rel/family-spending/familyspending/family-spending-2011-edition/sum-consumer-durablesnugget.html. Accessed: April 2012.

Pakula. C \& R. Stamminger. 2010. "Electricity and water consumption for laundry washing by washing machine worldwide." Energy Efficiency. Springer Publishing, Netherlands.

Pink, S. 2005. "Dirty Laundry. Everyday practice, sensory engagement and the constitution of identity". Social Anthropology, 13, 275-290.

Renström, S., Strömberg, H., and Selvefors, A. 2013. "Pathways of Sustainable Behaviours". 16th Conference of the European Roundtable on Sustainable Consumption and Production (ERSCP) \& 7th Conference of the Environmental Management for Sustainable Universities (EMSU) (ERSCP-EMSU 2013), Istanbul, Turkey, 4th-7th June 2013.

Shove, E. 2003. Comfort, Cleanliness and Convenience, Oxford: Berg.

Shove, E. 2003b. "Converging conventions of comfort, cleanliness and convenience". Journal of Consumer Policy, 26 (4). pp. 395-418. ISSN 0168-7034 
Spencer, J. \& Lilley, D. 2012. "The effect of culture on sustainable behaviour in a design context". Proceedings of 2nd PERL International Conference: Beyond Consumption; Pathways to sustainable living. Technische Universität Berlin.

Tang, T. 2010. "Towards sustainable use: design behaviour intervention to reduce household environment impact”. Design School PhD. Loughborough University

Uitdenbogerd, D.E. 2007. "Energy and Households - the Acceptance of Energy Reduction Options in Relation to the Performance and Organisation of Household Activities". Wageningen University.

Wever, R., Van Kuijk, J. \& Boks, C. 2008. "User-centred design for sustainable behaviour". International Journal of Sustainable Engineering, 1, 9 - 20. 